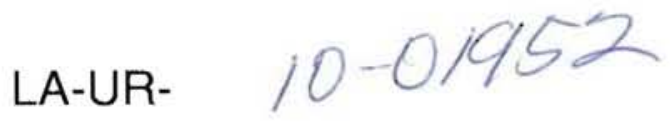

Approved for public release;

distribution is unlimited.

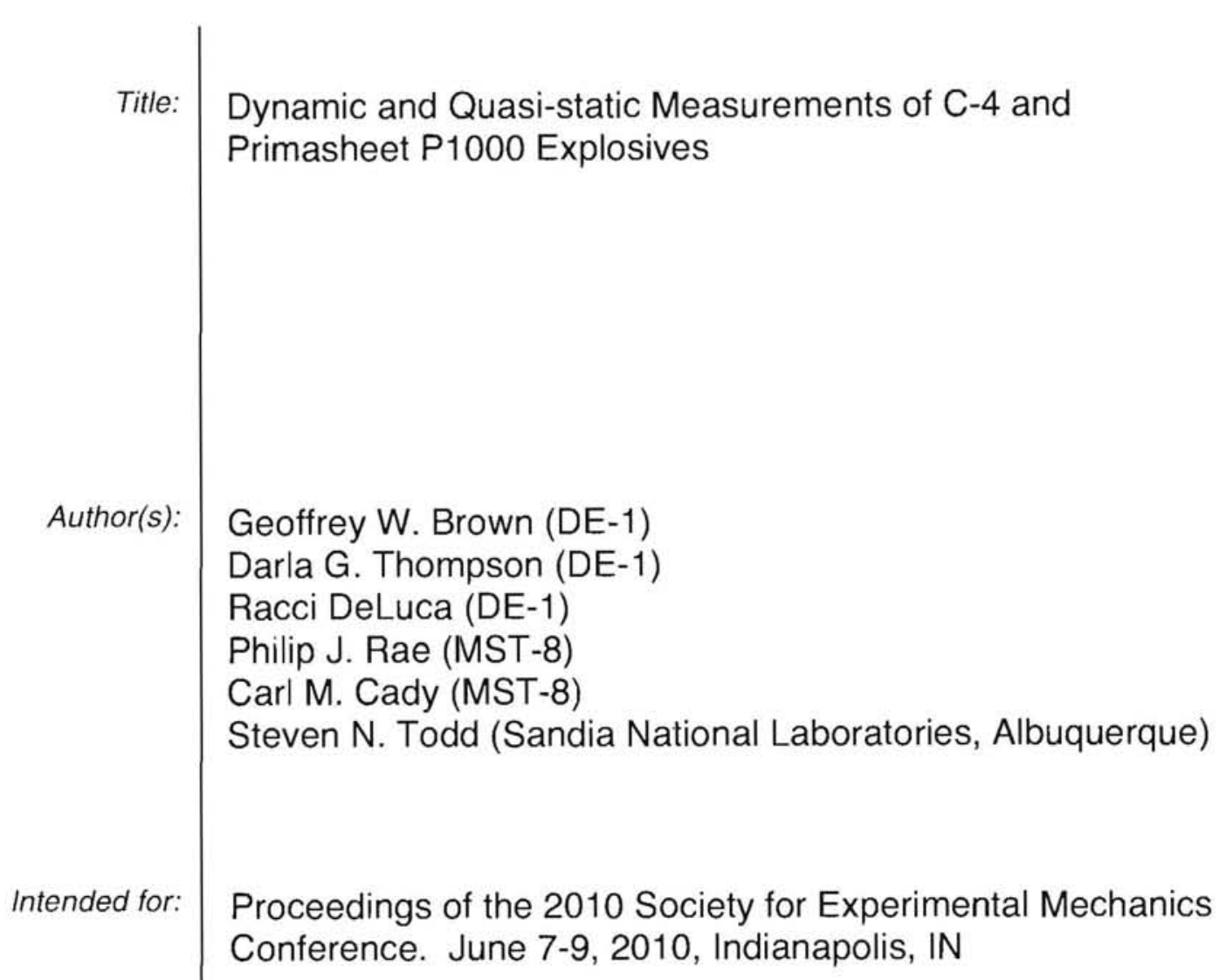

Los Alamos National Laboratory, an affirmative action/equal opportunity employer, is operated by the Los Alamos National Security, LLC for the National Nuclear Security Administration of the U.S. Department of Energy under contract DE-AC52-06NA25396. By acceptance of this article, the publisher recognizes that the U.S. Government retains a nonexclusive, royalty-free license to publish or reproduce the published form of this contribution, or to allow others to do so, for U.S. Government purposes. Los Alamos National Laboratory requests that the publisher identify this article as work performed under the auspices of the U.S. Department of Energy. Los Alamos National Laboratory strongly supports academic freedom and a researcher's right to publish; as an institution, however, the Laboratory does not endorse the viewpoint of a publication or guarantee its technical correctness. 


\title{
Dynamic and Quasi-static Measurements of C-4 and Primasheet P1000 Explosives
}

\author{
Geoffrey W. Brown ${ }^{1, a}$, Darla G. Thompson ${ }^{1}$, Racci DeLuca ${ }^{1}$, Philip J. Rae ${ }^{2}$, Carl M. Cady ${ }^{2}$, and \\ Steven N. Todd ${ }^{3}$ \\ ${ }^{1}$ High Explosive Science \& Technology (DE-1), ${ }^{2}$ Materials Science \& Technology (MST-8), LoS \\ Alamos National Laboratory, Los Alamos, NM \\ ${ }^{3}$ Energetic Systems Research (5916) and Systems Assessment and Research Center (5900), \\ Sandia National Laboratories, Albuquerque, NM \\ ${ }^{a}$ Corresponding author: MS C920, Los Alamos National Laboratory, Los Alamos, NM 87545. \\ email: geoffb@lanl.gov
}

\begin{abstract}
We have measured dynamic and quasi-static mechanical properties of C-4 and Primasheet P1000 explosive materials to provide input data for modeling efforts. Primasheet P1000 is a pentaerythritol tetranitrate-based rubberized explosive. C-4 is a RDX-based moldable explosive. Dynamic measurements included acoustic and split-Hopkinson pressure bar tests. Quasi-static testing was done in compression on load frames and on a dynamic mechanical analyzer. Split-Hopkinson and quasi-static tests were done at five temperatures from $-50^{\circ} \mathrm{C}$ to $50^{\circ} \mathrm{C}$. Acoustic velocities were measured at, above, and below room temperature.
\end{abstract}

\section{INTRODUCTION}

In this work we have measured the mechanical properties of C-4 and Primasheet P1000 explosive materials. The data will be used as input for a Damage-Induced Reaction Model [1] (DMGIR) that can predict non-shock-induced initiation. As in the development of other physics codes, the mechanical property data measured here contribute to constitutive relations that are used in equation-of-state models implemented in the code. P1000 and C-4 are relevant materials for DMGIR development and validation because they are used in a number of different explosives applications and because they can be considered representative "rubberized" and "moldable" explosive materials, respectively, to evaluate model capabilities. In previous work we have evaluated "pressed" and "cast" explosive materials for the same purposes [2].

\section{EXPERIMENT}

In this work we have measured dynamic and quasi-static mechanical properties of both materials. Dynamic measurements were made using split-Hopkinson pressure bar (SHPB) and acoustic testing. Quasi-static testing was carried out on mechanical load frames and on a dynamic mechanical analyzer (DMA). All quasi-static testing was done in compression.

Split-Hopkinson pressure bar (SHPB) tests were carried out with a custom made instrument [3]. The system has an environmental chamber that maintains the sample at various temperatures between $-50^{\circ} \mathrm{C}$ and $50^{\circ} \mathrm{C}$ prior to testing. Maraging steel bars were used in these experiments. Over the $+1-50^{\circ} \mathrm{C}$ temperature range used in these experiments, the impedance of the Maraging steel changes negligibly. Molybdenum grease was used to lubricate the $\mathrm{P} 1000$ sample ends but no lubricant was used on the $\mathrm{C}-4$. Samples were tested at $-50^{\circ} \mathrm{C},-15^{\circ} \mathrm{C}, 0^{\circ} \mathrm{C}, 21^{\circ} \mathrm{C}$, and $50^{\circ} \mathrm{C}$. SHPB samples for both materials were 0.125 inch thick disks, 0.25 inches in diameter. For P1000, the 
strain-rates were typically $3000 \mathrm{~s}^{-1}$ except at $-50{ }^{\circ} \mathrm{C}$ where it was $2000 \mathrm{~s}^{-1}$. For $\mathrm{C}-4$, all strain-rates were approximately $5000 \mathrm{~s}^{-1}$.

Quasi-static testing of P1000 at a strain rate of $33 \mathrm{~s}^{-1}$ was carried out on a commercial load frame (MTS model 810 with a high-rate valve). Specimens were compressed between polished tungsten carbide platens lubricated with molybdenum grease to reduce end face friction. The platens were heated or cooled and surrounding insulation provided control of the sample temperature. Samples were tested at $-50^{\circ} \mathrm{C},-15^{\circ} \mathrm{C}, 0^{\circ} \mathrm{C}, 20^{\circ} \mathrm{C}$, and $50^{\circ} \mathrm{C}$. Quasistatic samples for both materials were 0.25 inch thick cylinders, 0.25 inches in diameter.

Quasi-static testing of both materials at strain rates of $0.025 \mathrm{~s}^{-1}$ and $0.0025 \mathrm{~s}^{-1}$ was carried out on a second commercial load frame (MTS Instron 5567). Specimens were compressed between stainless steel platens. Tests with and without lubricated end faces did not show significant differences. No lubrication was used on the C-4 samples. All testing was done in an environmental chamber using heated or cooled air flow to maintain the desired temperature. Samples were tested at $-50^{\circ} \mathrm{C},-25^{\circ} \mathrm{C}, 0^{\circ} \mathrm{C}, 25^{\circ} \mathrm{C}$, and $50^{\circ} \mathrm{C}$. For these tests, samples of both materials were 0.5 inch thick cylinders, 0.25 inches in diameter.

Acoustic wave velocities were measured using a time-of-flight method illustrated schematically in Figure 1. For each sample, the transit times of the initial peaks in the longitudinal and shear wave signals were measured both with and without the explosive sample in the transducer-delay bar stack. Knowing the sample thickness, the difference in transit times with and without the sample present then gives the acoustic wave velocity. An aluminum delay bar was used for all samples and all testing was done with commercial transducers having $1 \mathrm{MHz}$ resonance frequencies. For both materials, we attempted to measure acoustic velocities at three different thicknesses and at temperatures below, at, and above room temperature. The actual sample sizes and temperatures are described in Table 1. For the P1000 material, thickened honey was used to couple the transducers to the samples. No couplant was used for the C-4 samples.

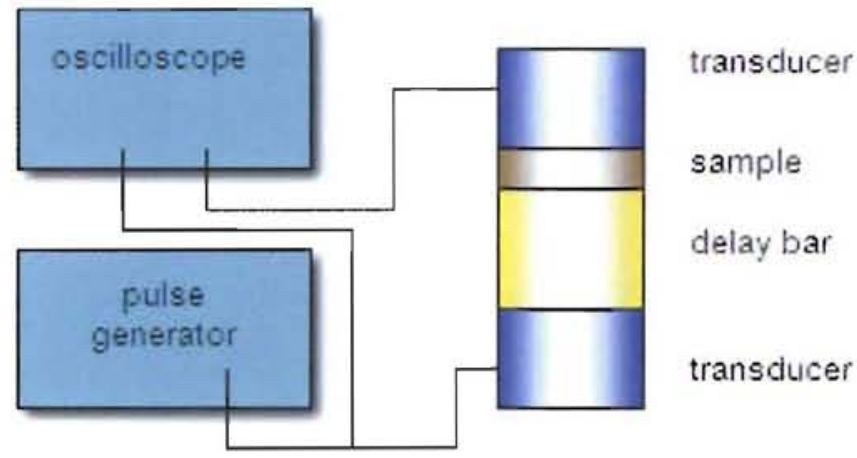

Figure 1. Schematic illustration of acoustic velocity measurement instrumentation.

Dynamic mechanical analysis (DMA) was carried out using a commercial instrument (TA Instruments Q800). The samples were held in stainless steel compression clamps inside the environmental housing with integral electric heaters. For the cold tests, liquid nitrogen vapor is flowed through the housing. P1000 samples were 0.25" diameter disks of thicknesses $2 \mathrm{~mm}, 3 \mathrm{~mm}$, and $4 \mathrm{~mm}$. The C-4 samples were nominally 0.25 " thick disks, 0.25 " in diameter. No lubricant was used for any DMA samples.

\section{SAMPLE MATERIALS}

Primasheet $\mathrm{P} 1000$ is a rubberized explosive that is nominally $63 \%$ pentaerythritol tetranitrate by weight with $8 \%$ nitrocellulose and $27 \%$ binder. The binder was not specified for the samples used in this work. For all measurements, cylindrical samples were hand cored from sheets of P1000. Sheets above $4 \mathrm{~mm}$ thickness were just stacks of the thinner sheets bonded together.

C-4 is a moldable explosive that is nominally $91 \%$ hexahydrotrinitrotriazine (RDX) in $9 \%$ oil or oil/polymer mixture. The material came in large prefabricated blocks and test samples were made by hand pressing small pieces of the block into molds. The density of the hand-pressed parts was less than that of the block but the composition of the material made it difficult to measure the dimensions or density of any samples. All results on C-4 should be considered typical of "worked" or "molded" material. 


\section{RESULTS}

\section{Primasheet P1000 Results}

The SHPB results for $\mathrm{P} 1000$ at the temperature endpoints of $+1-50^{\circ} \mathrm{C}$ are shown in Figure 2. Each plot has traces from three different tests illustrating the sample-to-sample variability. The progression of the curves between these temperature endpoints can be seen in the right panel of Figure 3.

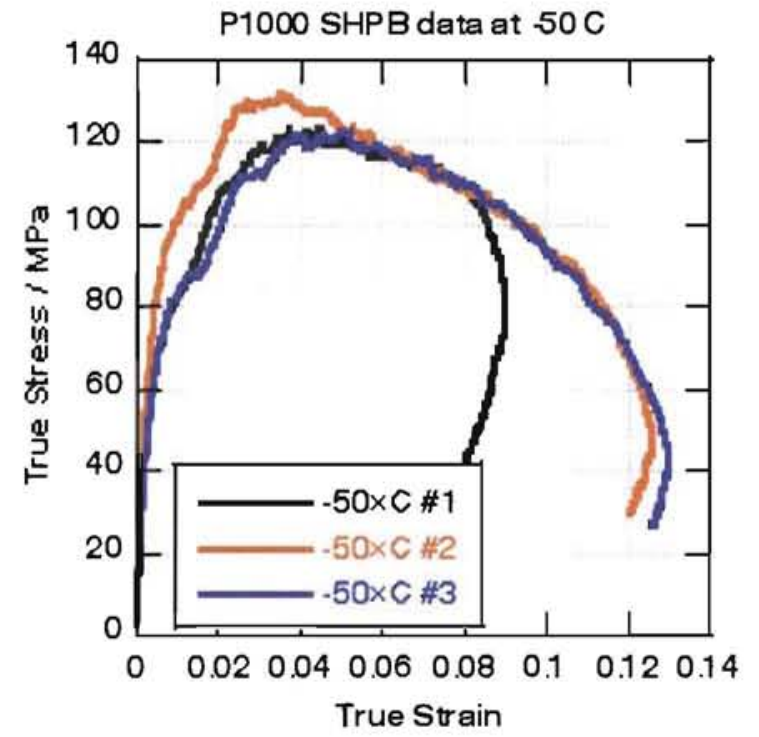

Figure 2. SHPB data from $\mathrm{P} 1000$ at $-50^{\circ} \mathrm{C}$ and $50^{\circ} \mathrm{C}$.

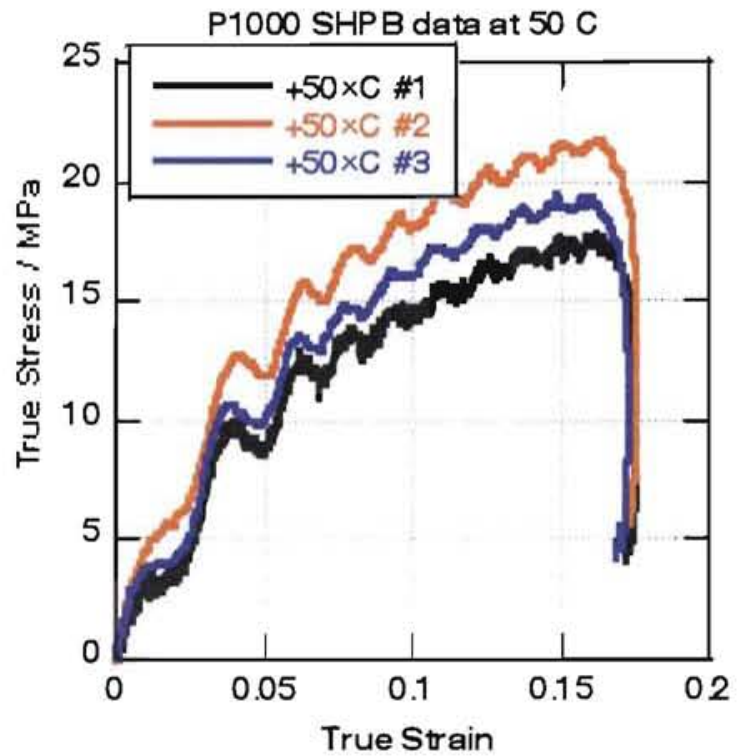

An example of the equilibrium region of the P1000 SHPB data can be seen from the "1-wave","2-wave" plots shown in the left panel of Figure 3. "1-wave" traces are the transmitted bar signals while "2-wave" traces are the sums of synchronized incident and reflected bar signals [4]. Typically, SHPB data is a valid measurement of the sample properties in regions where the 2-wave signal oscillates around the 1-wave signal and where the strain rate is roughly constant. For the P1000 data sets here, this region is roughly between $2 \%$ and $10 \%$ strain. Before $2 \%$ strain, the system has not reached equilibrium and after $10 \%$ strain, the signals are primarily related to damage accumulation in the sample. Example P1000 SHPB data for all temperatures is the right panel.
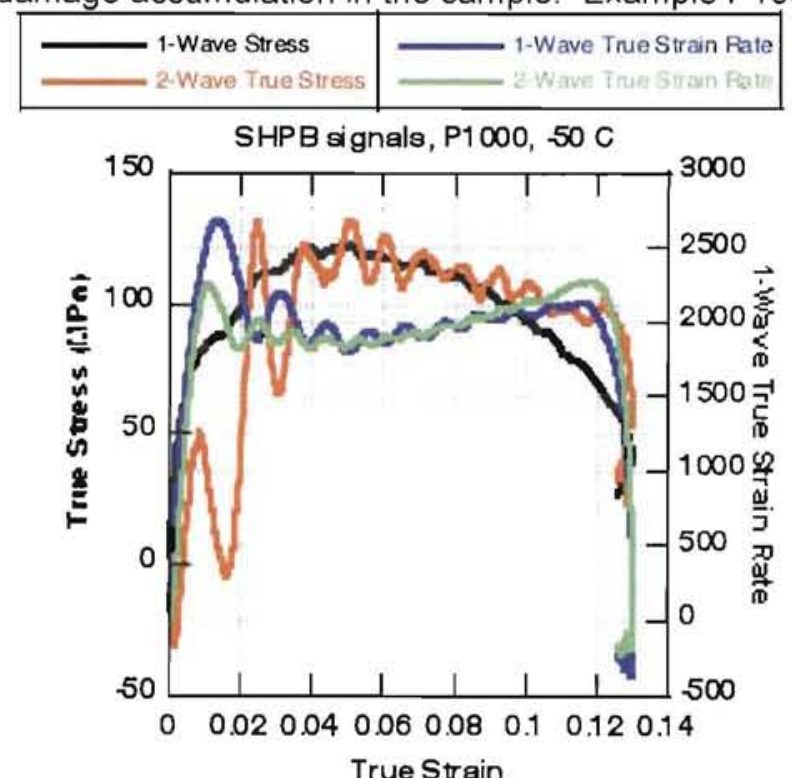

P1000 SHPB Temperature Dependence

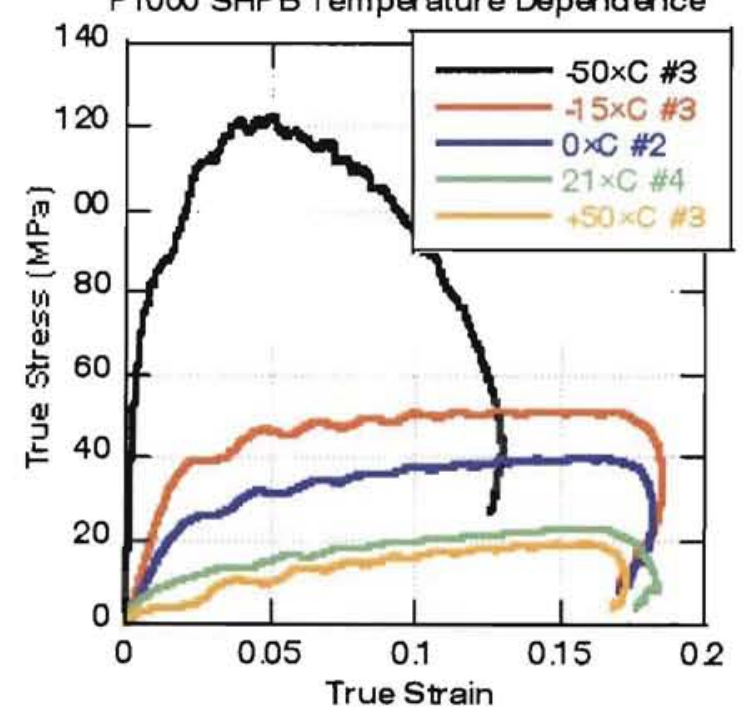

Figure 3. (left) SHPB stress and strains for one test on $\mathrm{P} 1000$ at $-50^{\circ} \mathrm{C}$. (right) Compilation of representative SHPB data for P1000 at all temperatures tested.

Quasi-static testing results for $\mathrm{P} 1000$ at $33 \mathrm{~s}^{-1}$ and $0.025 \mathrm{~s}^{-1}$ strain rates are shown in Figure 4. Tests at $0.0025 \mathrm{~s}^{-1}$ were similar to those shown in the right panel. Details of the maximum stress values are in Figure 9. 
P1000, 33s-1 data

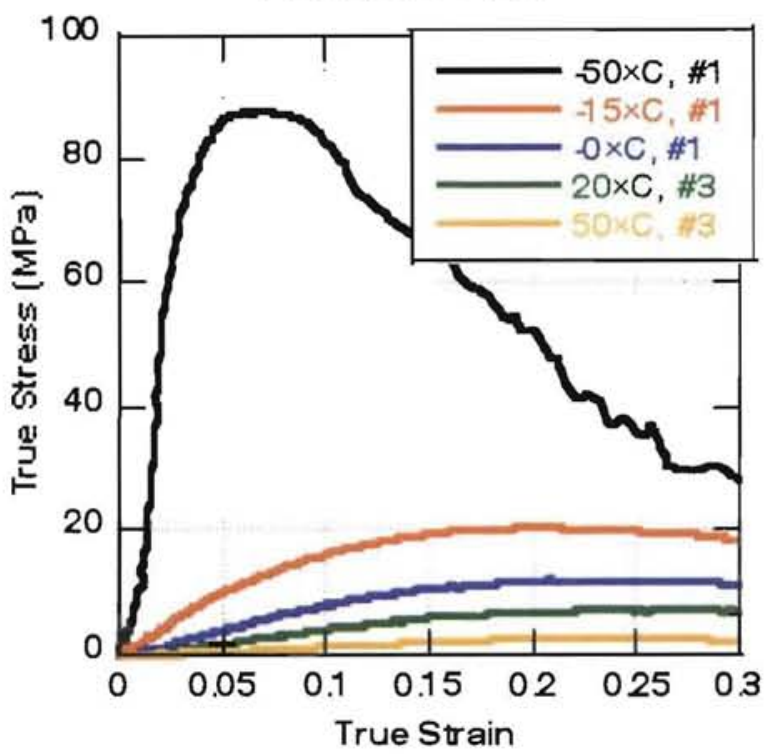

$\mathrm{P} 1000,0.025 \mathrm{~s}-1$ data

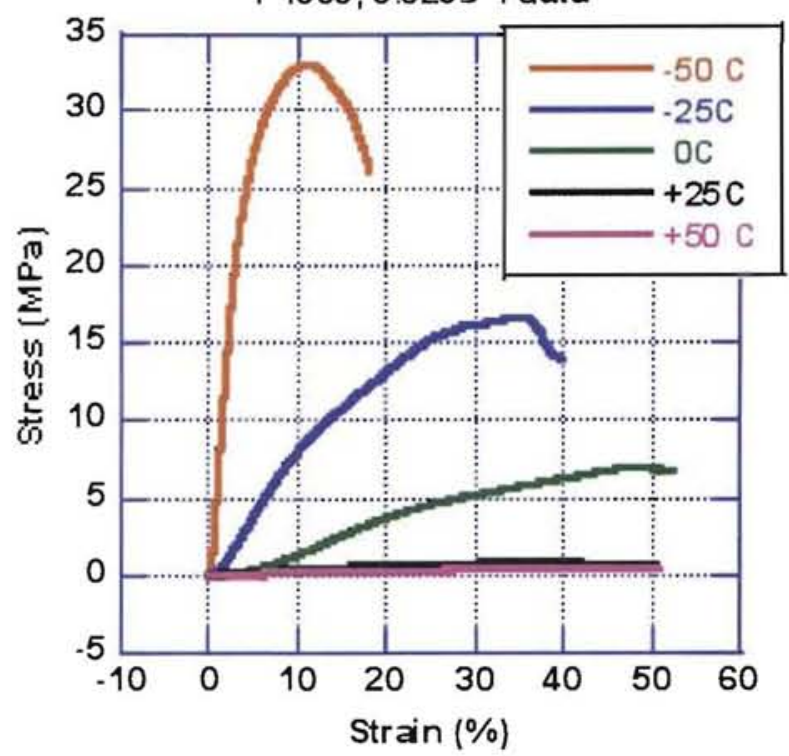

Figure 4. Quasi-static compression data for P1000 over the full temperature range.

DMA results are shown in the left panel of Figure 5. Samples were tested in compression disk platen fixtures at 1 $\mathrm{Hz}$ and $10 \mathrm{~Hz}$ with 5 micron amplitude setpoint and $0.2 \mathrm{~N}$ static applied force. A value of 0.44 was assumed for Poisson's ration for calculations. In practice, the stiffness of the samples at low temperatures exceeded the instrument measurement capability. Samples were therefore ramped down in temperature from $50^{\circ} \mathrm{C}$ at a rate of $0.5^{\circ} \mathrm{C} / \mathrm{min}$ until the instrument limit was reached. The right panel shows the thermal contraction during this cool down as measured in the DMA. The $2 \mathrm{~mm}$ and $4 \mathrm{~mm}$ thick samples behave similarly while the $3 \mathrm{~mm}$ samples exhibit different behavior. We examined all sheets of material with differential scanning calorimetry (data not shown) but did not observe any obvious compositional differences between the sheets.
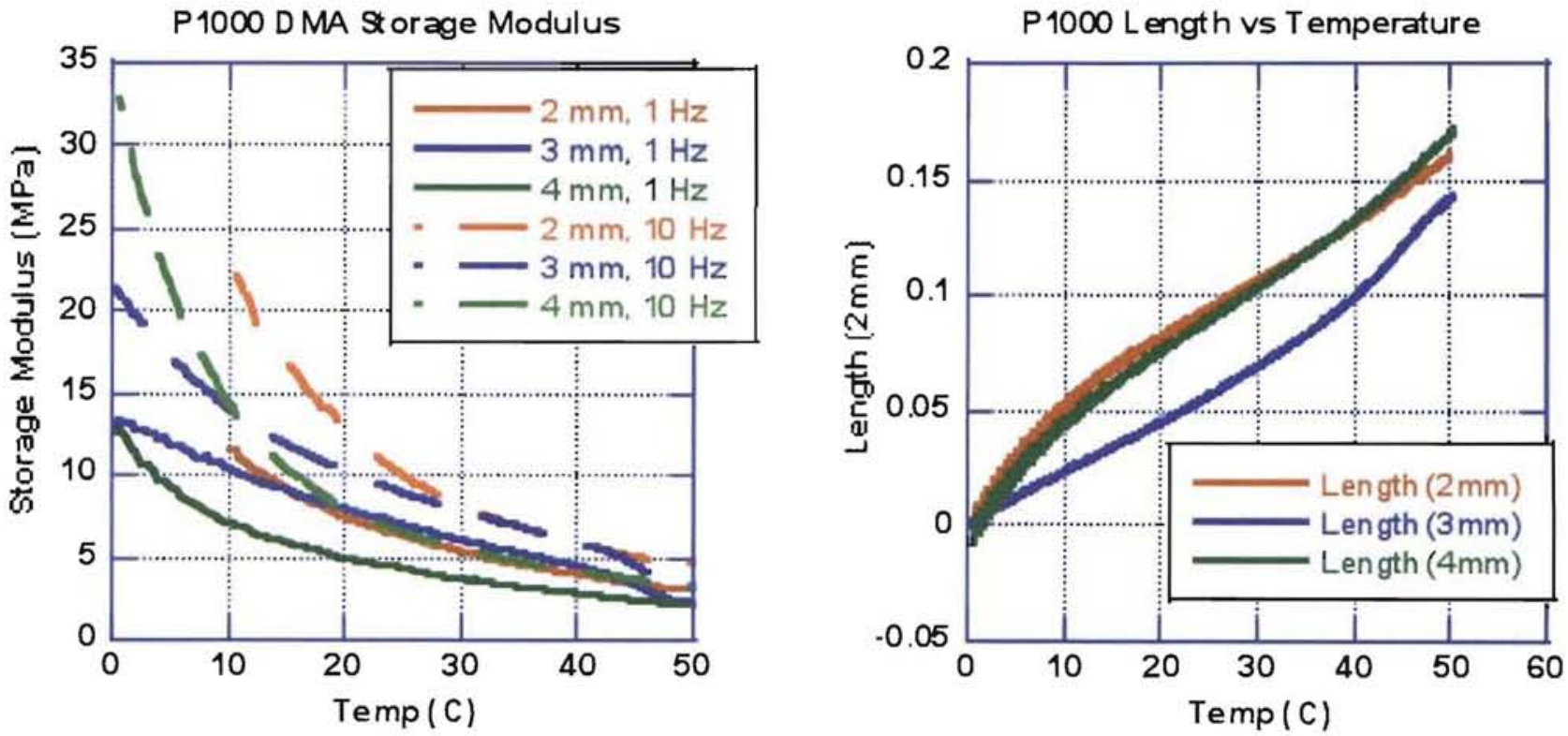

Figure 5. DMA results from P1000 showing moduli (left) and thermal contraction (right). 


\section{C-4 Results}

The SHPB results for $\mathrm{C}-4$ at the temperature endpoints of $-50^{\circ} \mathrm{C}$ and $20^{\circ} \mathrm{C}$ are shown in Figure 6 . Each plot has traces from three different tests illustrating the sample-to-sample variability. The variability is large for these hand-pressed samples. Example plots at intermediate temperatures are shown in the right panel of Figure 7.
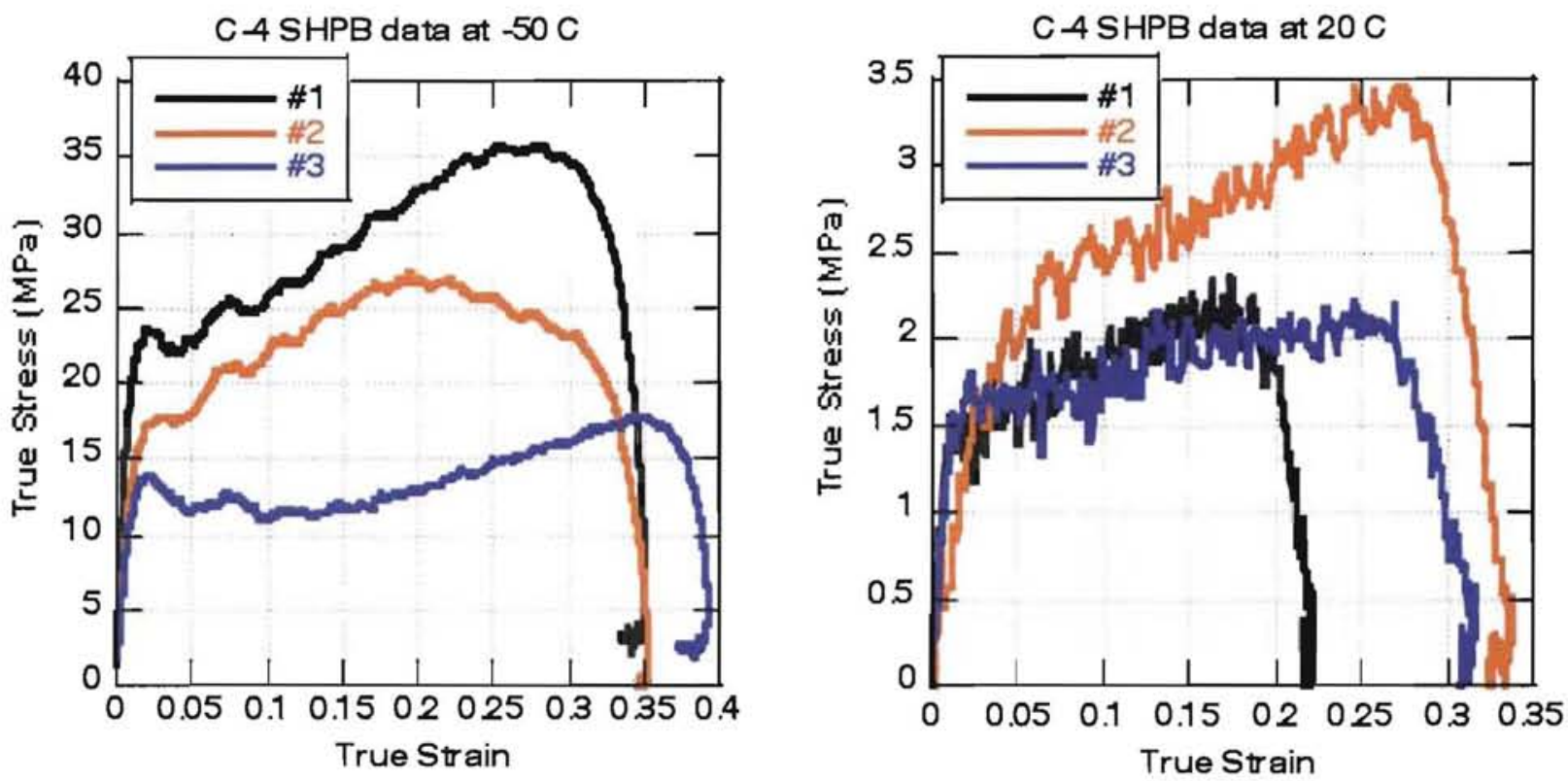

Figure 6. SHPB data from C-4 at $-50^{\circ} \mathrm{C}$ and $50^{\circ} \mathrm{C}$.

The equilibrium region of the C-4 SHPB data can be seen from "1-wave"-"2-wave" plots shown in the left panel of Figure 7 for the $-50^{\circ} \mathrm{C}$ data set. For these soft samples, the equilibrium region is between around $1 \%$ and $3 \%$ strain. Example C-4 SHPB data for all temperatures is compiled in the right panel of Figure 7.
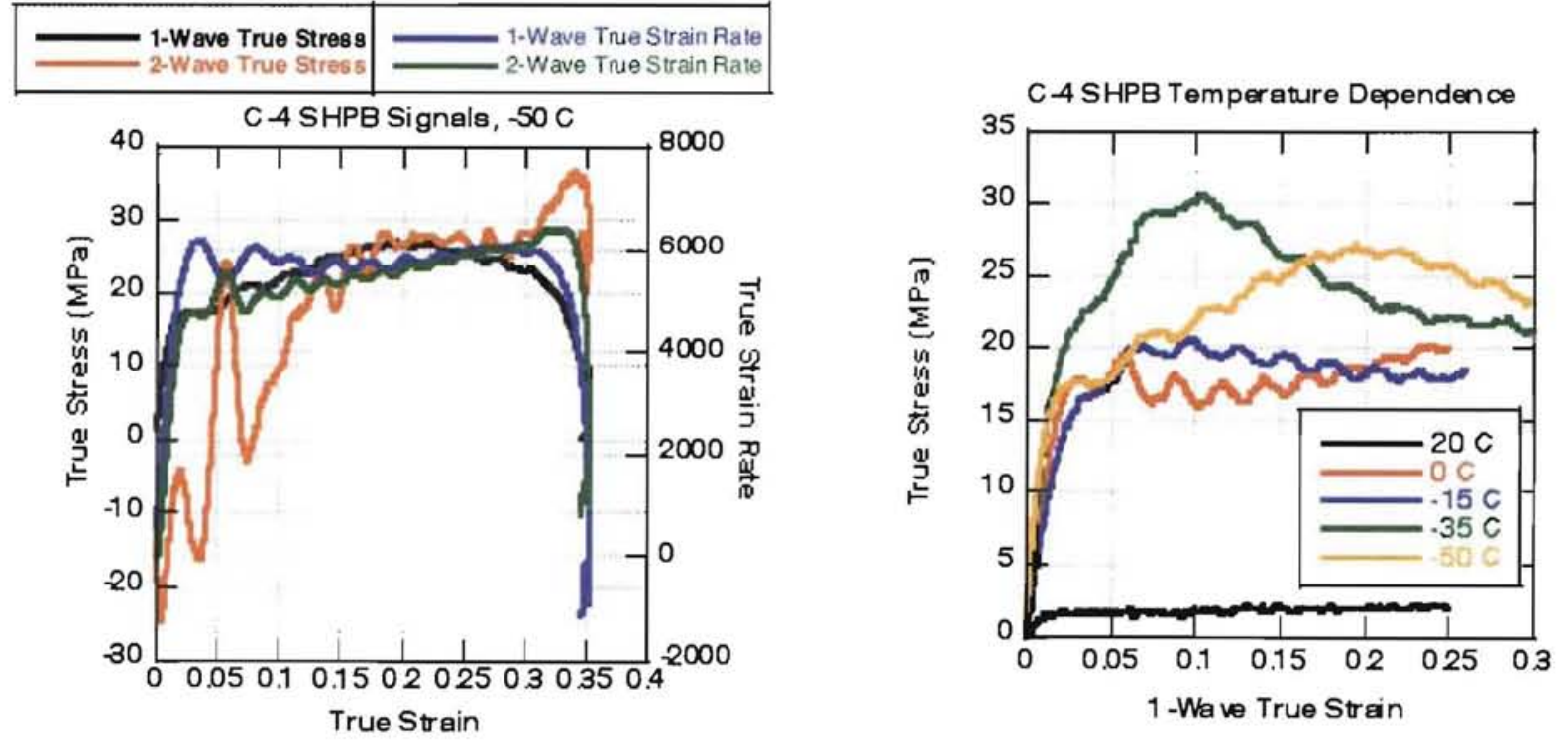

Figure 7. (left) SHPB stress and strains for one test on $\mathrm{C}-4$ at $-50^{\circ} \mathrm{C}$. (right) Compilation of representative SHPB data for $\mathrm{C}-4$ at all temperatures tested. 
Quasi-static testing results for C-4 at all temperatures are shown in Figure 8. The load frame testing at the slowest strain rate is not shown but had similar characteristics to the curves in the left panel. The data in the right panel are constant force compression response plots acquired in the DMA instrument without modulation. The softness of the material made it virtually impossible to sustain any appreciable stable modulation. Samples were compressed between the platens at rates of $0.8,0.6,0.4,0.2$, and $0.1 \mathrm{~N} / \mathrm{m}$ from $-50^{\circ} \mathrm{C}$ to $50^{\circ} \mathrm{C}$. Variation of the ramp rate was necessary to maintain stable instrument control at each temperature. It was generally necessary to slow the ramp rate as the temperature was increased and the sample became softer. The first knee in the plots represents macroscopic failure of the pressed sample while the second upturn is the start of recompression of the material as the platens continue to move together.
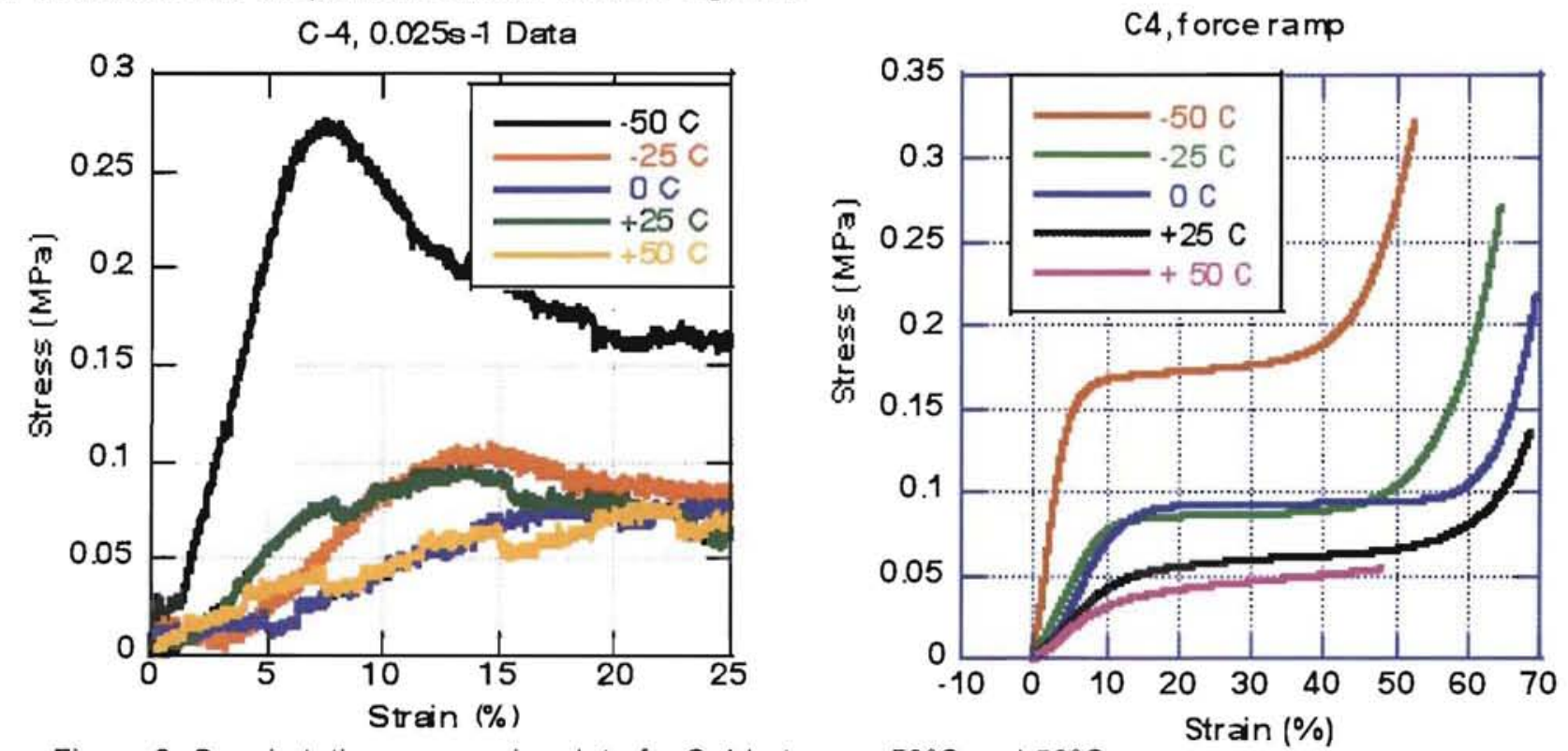

Figure 8. Quasi-static compression data for $\mathrm{C}-4$ between $-50^{\circ} \mathrm{C}$ and $50^{\circ} \mathrm{C}$.

The maximum stress vs. temperature results for all constant strain rate tests are compiled in Figure 9.
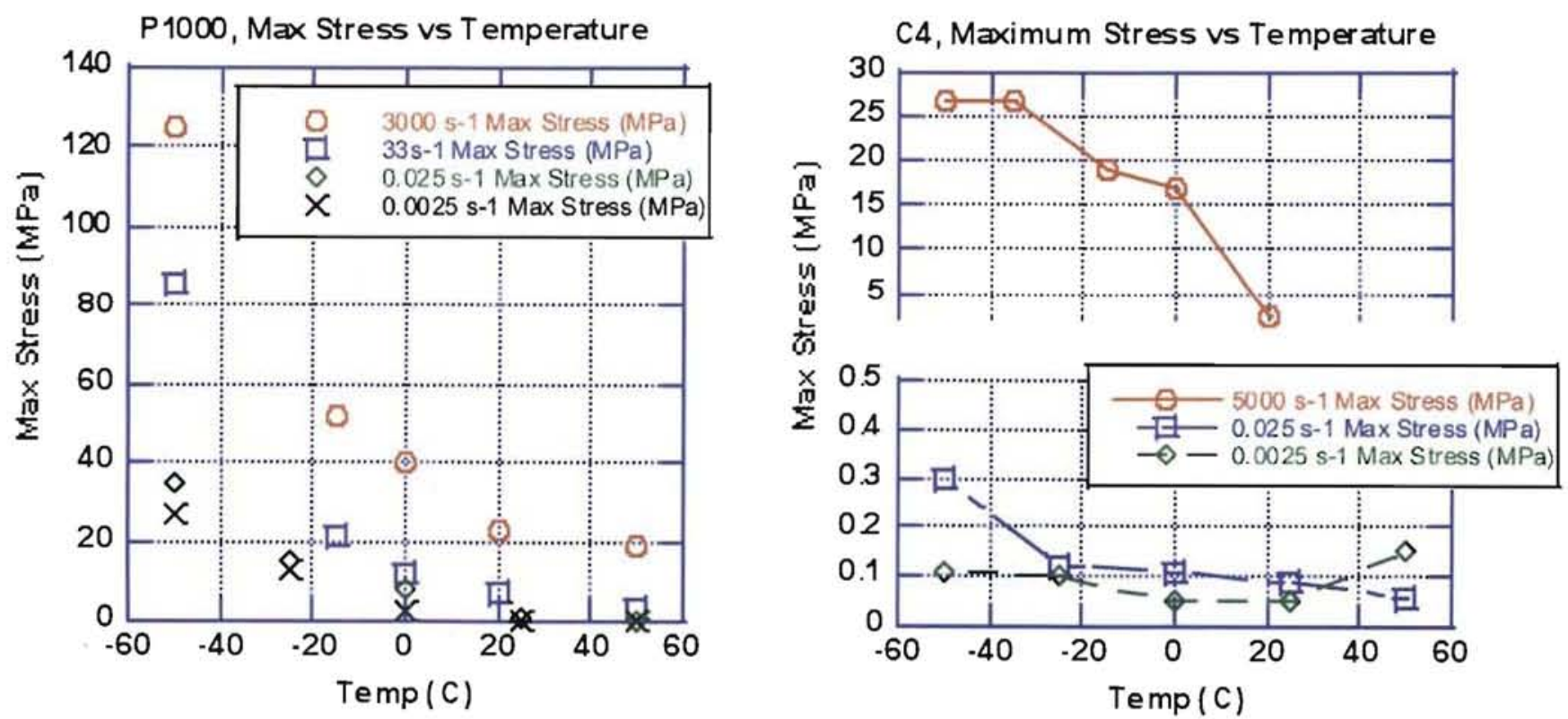

Figure 9. Maximum material stress for $\mathrm{P} 1000$ (left) and C-4 (right) vs. temperature and strain rate. 


\section{Acoustic Results}

Table 1 shows the acoustic velocities measured for both materials. As with the thermal contraction, the $3 \mathrm{~mm}$ thick P1000 samples were significantly different from the $2 \mathrm{~mm}$ and $4 \mathrm{~mm}$ samples and we have presented the two sets of results separately in the table. For all of the data in the table, the values are generally the average of multiple measurements from at least three different samples. However, for the case of $\mathrm{C}-4$ at $34^{\circ} \mathrm{C}$, only the 0.9 $\mathrm{mm}$ thick samples provided data since the signal was too heavily attenuated in the thicker samples. In addition, for $\mathrm{P} 1000$ at $9^{\circ} \mathrm{C}$ and $23^{\circ} \mathrm{C}$, the $2 \mathrm{~mm}$ samples were considered as part of the delay bar in order to calculate the shear wave velocities since the signal shape with any P1000 present was significantly different from the shape transmitted through the delay bar alone.

Table 1. Acoustic velocities measured for $\mathrm{P} 1000$ and $\mathrm{C}-4$ materials. $V_{\mathrm{L}}$ is longitudinal speed and $\mathrm{V}_{\mathrm{S}}$ is shear speed.

\begin{tabular}{|c|c|c|c|c|}
\hline Material & $\begin{array}{c}\text { Temperature } \\
(\mathrm{C})\end{array}$ & $\begin{array}{c}\text { Thicknesses } \\
(\mathrm{mm})\end{array}$ & $V_{L}(\mathrm{~km} / \mathrm{sec})$ & $V_{S}(\mathrm{~km} / \mathrm{sec})$ \\
\hline & & 2,4 & 1.82 & 1.84 \\
\hline P1000 & 9 & 2,4 & 1.71 & 1.68 \\
\hline P1000 & 23 & 2,4 & 1.63 & 1.60 \\
\hline P1000 & 34 & 3 & 1.67 & 1.58 \\
\hline P1000 & 9 & 3 & 1.62 & 1.49 \\
\hline P1000 & 23 & 3 & 1.55 & 1.53 \\
\hline P1000 & 34 & & & 0.27 \\
\hline & 9 & $0.9,1.8,2.7$ & 0.83 & 0.37 \\
\hline C-4 & 23 & $0.9,1.8,2.7$ & 0.96 & 0.21 \\
\hline C-4 & 34 & 0.9 & 0.70 & \\
\hline C-4 & & & & \\
\hline
\end{tabular}

\section{DISCUSSION}

\section{P1000}

The dynamic and quasi-static test results for $\mathrm{P} 1000$ show a changing behavior over the temperature range examined. At $-50^{\circ} \mathrm{C}$ and $-25^{\circ} \mathrm{C}$, the material is brittle and loads to failure in the SHPB and load frame tests. Above $-25^{\circ} \mathrm{C}$, however, there is indication of constant flow stress after the initial rapid loading followed by abrupt failure near $17 \%$ strain, regardless of temperature. In the load frame tests, above $-25^{\circ} \mathrm{C}$, abrupt failure is not observed and the sample is able to plastically deform over a large strain range. It is likely that the temperature dependence is due to a glass transition in the binder - the overall behavior is then what one would expect for a rubber material.

The $1 \mathrm{~Hz}$ and $10 \mathrm{~Hz}$ DMA storage moduli reflect the material's elastic response at low frequencies and small amplitudes. The peak strain rate during these tests is in the range of $0.0008 \mathrm{~s}^{-1}$ to $0.008 \mathrm{~s}^{-1}$ for $1 \mathrm{~Hz}$ and $10 \mathrm{~Hz}$ tests, respectively. The maximum stress at these strain rates vs. temperature is also consistent with the data from the other testing methods plotted in Figure 9.

The thermal contraction differences provide the clearest indication that the $3 \mathrm{~mm}$ thick $\mathrm{P} 1000$ material differs from the $2 \mathrm{~mm}$ and $4 \mathrm{~mm}$ thick materials. In the absence of obvious compositional differences, the $3 \mathrm{~mm}$ thick P1000 samples may have a binder material with the same chemical composition but slightly different polymeric properties, such as molecular weight or cross-link density. This would also be consistent with the lower storage modulus of the $3 \mathrm{~mm}$ thick samples at lower temperatures - if they have a lower glass transition temperature, they will appear softer as the testing temperature drops nearer to the glass transition of the $2 \mathrm{~mm}$ and $4 \mathrm{~mm}$ samples. 


\section{C-4}

The C-4 data are less straightforward to interpret because of the large amount of variability in the replicate tests. This is likely due to the variability inherent in hand forming these moldable materials. It does illustrate the possible range of response that may be encountered in tests of materials that are very soft and easily deform during the handling necessary for mounting in the instruments. The data are also relevant to applications in which the prefabricated blocks must be deformed to match a specific shape.

In general the C-4 SHPB data shows rapid loading and ranges of constant flow stress at some temperatures before relatively abrupt failure. The load frame data shows similar results although the variability in the temperature dependent results above $-50^{\circ} \mathrm{C}$ is large. The variability is less in the DMA compression data, which shows a decreasing elastic modulus with temperature and failure at around $10 \%$ strain.

An interesting observation is the point at which the temperature dependence has its largest change in the various tests. For the SHPB data, this occurs when going from $0^{\circ} \mathrm{C}$ to $20^{\circ} \mathrm{C}$. For the load frame and DMA tests this occurs when going from $-50^{\circ} \mathrm{C}$ to $-25^{\circ} \mathrm{C}$.

\section{Acoustic Results}

The acoustic velocities for $\mathrm{P} 1000$ are similar to what would be expected for other medium-soft rubber materials such as neoprene (typically $1.6 \mathrm{~km} / \mathrm{s}$ ). They are slightly higher due to the increase in density from the addition of PETN $\left(1.77 \mathrm{~g} / \mathrm{cm}^{3}\right.$ compared to $1.23 \mathrm{~g} / \mathrm{cm}^{3}$ for neoprene for example). The lower velocities in the $3 \mathrm{~mm}$ thick samples would indicate that they are slightly softer materials, consistent with the storage modulus results from DMA. The acoustic velocities of the C-4 samples likely reflect the low density and sample-to-sample variation resulting from hand pressing the parts.

\section{REFERENCES}

[1] Todd, S.N., Vogler, T.J., Caipen, T.L., and Grady, D.E., "Non-shock initiation model for plastic bonded explosive PBXN-5: Theoretical Results", Shock Compression of Condensed Matter - 2007, CP955, pp. 1006 1009, 2007.

[2] Brown, G.W., Tencate, J.A., DeLuca, R., Rae, P.J., Todd, S.N., "Dynamic and Quasi-static Measurements of PBXN-5 and Comp-B Explosives", Society for Experimental Mechanics - 2009 SEM Annual Conference Proceedings", Vol 2, pp. 731-738, 2009.

[3] Gray III, G.T., and Blumenthal, W.R. "Split-Hopkinson pressure bar testing of soft materials", ASM Handbook, Volume 8-Mechanical Testing and Evaluation, ASM International, pp. 488 - 496, 2000.

[4] Gray III, G.T., Idar, D.J., Blumenthal, W.R., Cady, C.M., and Peterson, P.D., "High-and-low strain rate compression of several energetic material composites as a function of strain rate and temperature", $11^{\text {th }}$ International Detonation Symposium, 1998. 